\title{
Factors Influencing Vaccination in Korea: Findings From Focus Group Interviews
}

\author{
Bomi Park', Eun Jeong Choi', Bohyun Park', Hyejin Han', Su Jin Cho², Hee Jung Choi ${ }^{3}$, Seonhwa Lee', Hyesook Park' \\ ${ }^{1}$ Department of Preventive Medicine, Ewha Womans University School of Medicine, Seoul, Korea; '2Department of Pediatrics, Ewha Womans \\ University School of Medicine, Seoul, Korea; ${ }^{3}$ Department of Internal Medicine, Ewha Womans University School of Medicine, Seoul, Korea
}

Objectives: Immunization is considered one of the most successful and cost-effective public health interventions protecting communities from preventable infectious diseases. The Korean government set up a dedicated workforce for national immunization in 2003, and since then has made strides in improving vaccination coverage across the nation. However, some groups remain relatively vulnerable and require intervention, and it is necessary to address unmet needs to prevent outbreaks of communicable diseases. This study was conducted to characterize persistent challenges to vaccination.

Methods: The study adopted a qualitative method in accordance with the Consolidated Criteria for Reporting Qualitative Research checklist. Three focus group interviews were conducted with 15 professionals in charge of vaccination-related duties. The interviews were conducted according to a semi-structured guideline, and thematic analysis was carried out. Data saturation was confirmed when the researchers agreed that no more new codes could be found.

Results: A total of 4 main topics and 11 subtopics were introduced regarding barriers to vaccination. The main topics were vaccine hesitancy, personal circumstances, lack of information, and misclassification. Among them, vaccine hesitancy was confirmed to be the most significant factor impeding vaccination. It was also found that the factors hindering vaccination had changed over time and disproportionately affected certain groups.

Conclusions: The study identified ongoing unmet needs and barriers to vaccination despite the accomplishments of the National Immunization Program. The results have implications for establishing tailored interventions that target context- and group-specific barriers to improve timely and complete vaccination coverage.

Key words: Vaccination, Vaccination refusal, Focus groups, Immunization, Korea

\section{INTRODUCTION}

Immunization is considered one of the most successful and cost-effective public health interventions protecting commu-

Received: March 8, 2018 Accepted: May 25, 2018

Corresponding author: Hyesook Park, MD, PhD

Department of Preventive Medicine, Ewha Womans University School of Medicine, 1071 Anyangcheon-ro, Yangcheon-gu, Seoul 07985, Korea E-mail: hpark@ewha.ac.kr

This is an Open Access article distributed under the terms of the Creative Commons Attribution Non-Commercial License (http://creativecommons.org/licenses/bync/4.0/) which permits unrestricted non-commercial use, distribution, and reproduction in any medium, provided the original work is properly cited. nities from preventable infectious diseases [1,2]. The Korean government implemented the National Immunization Program in 2009 , and has gradually expanded the program to provide free vaccinations for all children under age 12 for designated diseases at community health centers and contracted clinics. Moreover, individual immunization records have been managed digitally since 2002 , enabling services such as providing an individual's immunization history for review and sending reminders of upcoming scheduled vaccinations. Such efforts resulted in the achievement of high rates (>92\%) of completing each recommended vaccination series among Korean 3-year-olds born in 2012 [3]. 
However, the proportion of infants who have completed the recommended number of vaccinations for their age declines with age, with a $95.9 \%$ timely and complete vaccination coverage at 12 months, a $92.7 \%$ at 24 months, and an $89.2 \%$ at 36 months. As can be seen from the 2014 measles outbreak in the US [4], nearly-disappeared epidemic diseases may reemerge at any time, especially if there are clusters of children with incomplete vaccinations. That outbreak demonstrated the importance of timeliness and completeness of vaccination.

The purpose of this study was to understand the remaining barriers to immunization, as well as unmet needs, despite the remarkable improvements in the economic and geographical accessibility of vaccination through the expansion of the $\mathrm{Na}$ tional Immunization Program. Focus group interviews were conducted to explore a deeper understanding of barriers to vaccination than would be provided from quantitative questionnaires.

\section{METHODS}

Focus group interviews were conducted with experts working in the immunization field to collect information based on their expertise and experience, with the purpose of identifying the barriers that lead to non-vaccination and unmet needs regarding vaccination. The focus group interview is a form of qualitative research in which a select group of people able to discuss an issue at a certain level are asked about their opinions, values, and beliefs during unstructured and natural discussions [5]. The method was described in accordance with the Consolidated Criteria for Reporting Qualitative Research checklist [6].

\section{Research Team and Reflexivity}

The research team consisted of 8 researchers, 4 of them (BP, SJC, HJC, HP) physicians and the other 4 (EJC, BP, HH, SL) students and professors in the preventive medicine field. $\mathrm{HP}$, a preventive medicine professional who has been conducting vaccination-related research, led the interviews.

\section{Participants}

Immunization administrators at Korea Centers for Disease Control and Prevention (KCDC)-referred community health centers, pediatricians, and experts on multicultural families, one of the most vulnerable groups, received an explanation of the purpose of the study and a letter soliciting participation. A total of 15 participants, including 10 community health center staff members, 2 pediatricians, and 3 multicultural family experts, were selected, and no participants dropped out during the research. The research team and the subjects met for the first time at the focus group interview site and had no personal relationships or interests with each other, allowing the experts to exchange ideas as candidly and freely as possible. No compensation was provided to the participants.

\section{Study Design}

The interview guidelines were developed based on a review of previous studies, and the semi-structured interview guidelines were completed after pediatrics and infectious disease specialists reviewed the inclusiveness of the items and the adequacy of the content. The moderator explained the background and purpose of the research and led the interview following the semi-structured guidelines shown in Table 1.

The interview was carried out in a conference room near Seoul Station for 2-3 hours per expert group, until it was apparent that no more new topics were emerging. HP mediated the conversation and BP took notes while making an audio recording, observing, and keeping records of the progress. The participants were divided into 3 groups according to their occupation for the interview, reaching theoretical saturation through interviews with multiple experts.

Table 1. Guidelines for focus group interview questions

\begin{tabular}{l}
\hline Group $\quad$ Guideline \\
\hline $1 \quad$ Barriers regarding missed vaccination \\
Do you experience many cases of delayed or missed vaccination? \\
What are the reasons for delayed or missed vaccination? \\
What burdens are felt by patients or caregivers regarding \\
vaccination? \\
What are the difficulties in practicing vaccination? \\
Demand for vaccination information and communication \\
Do you receive requests for consultation or complaints \\
regarding vaccination? \\
If yes, what kind of people and what kind of information? \\
Do you think accurate and proper information is provided to \\
caregivers regarding vaccination? \\
Have you experienced difficulties in communication with \\
caregivers regarding vaccination? \\
Managing missed vaccination cases \\
Do you find it difficult to advise vaccination in cases of delayed \\
or missed vaccination? \\
What are the challenges in managing cases of missed \\
vaccination?
\end{tabular}




\section{Analysis}

The assistant moderator played the recorded audio immediately after the interview to make sure that every detail was available for analysis. By applying thematic analysis [7], one of the members (BP) performed initial coding and another (HP) reviewed the outcomes. The team reached agreement through debate when the 2 members disagreed, and the results of the analysis were reviewed by all members. Theoretical saturation was confirmed when the 2 researchers agreed that no additional codes could be found. The validity of the analysis was confirmed by an experienced infectious disease specialist who was neither a team member nor a participant. The results were not shared with the participants.

\section{Ethical Considerations}

This study was approved by the institutional review board (IRB) at Ewha Womans University (IRB no. EUMC-2016-11-035-002).

\section{RESULTS}

\section{Basic Attributes of the Participants}

Three expert groups including community health center immunization administrators, pediatricians, and multicultural family experts attended the interviews. A total of 10 community health center workers who had been in charge of immunization for 10 months to 4 years from Seoul (4 centers), Incheon (1 center), Daejeon (1 center), Gangwon (1 center), Gyeongbuk ( 2 centers), Jeonnam (1 center), Chungbuk (1 center), and Jeonbuk (1 center) attended the interviews. Two pediatricians were selected as participants, one of them chairman of the Korean Association of Pediatric Practitioners and the other a member of the Infectious Disease Committee of the Korea Pediatric Society who also is working as a university hospital pediatrician. As multicultural family experts, a family policy specialist at the Ministry of Gender Equality and Family, a Multicultural Family Support Center staff member at the Korean Institute for Healthy Family, and a consultant at the call center for multicultural families participated in the interview.

\section{Topics Introduced During the Focus Group Interview}

Vaccine hesitancy, personal circumstances that impede vaccination, lack of information, and misclassification emerged as the top 4 main reasons for non-vaccination. Each main topic could be divided into 2 to 3 subtopics (Table 2).
Table 2. Topics introduced in the focus group interviews

\begin{tabular}{|c|c|c|c|}
\hline Variables & $\begin{array}{l}\text { Community } \\
\text { health care } \\
\text { staff }\end{array}$ & Pediatrician & $\begin{array}{c}\text { Multicultural } \\
\text { family } \\
\text { experts }\end{array}$ \\
\hline \multicolumn{4}{|l|}{ Vaccine hesitancy } \\
\hline $\begin{array}{l}\text { Distrust in the safety of } \\
\text { vaccination }\end{array}$ & 0 & 0 & - \\
\hline $\begin{array}{l}\text { Suspicions about the } \\
\text { necessity of vaccination }\end{array}$ & 0 & 0 & - \\
\hline $\begin{array}{l}\text { Fear of side effects, } \\
\text { abnormal reactions }\end{array}$ & 0 & 0 & - \\
\hline \multicolumn{4}{|l|}{ Personal circumstances } \\
\hline Frequent overseas travel & 0 & 0 & 0 \\
\hline Double-income families & 0 & 0 & \\
\hline $\begin{array}{l}\text { Low accessibility of } \\
\text { medical institutions }\end{array}$ & 0 & - & 0 \\
\hline \multicolumn{4}{|l|}{ Lack of information } \\
\hline Multicultural families & 0 & - & 0 \\
\hline $\begin{array}{l}\text { Inaccurate contact } \\
\text { information }\end{array}$ & 0 & - & - \\
\hline \multicolumn{4}{|l|}{ Misclassification } \\
\hline Overseas residents & 0 & 0 & - \\
\hline Omitted input of records & 0 & 0 & - \\
\hline
\end{tabular}

\section{Vaccine hesitancy}

Community health center immunization administrators and pediatricians alike pointed to vaccine hesitancy as a major barrier, adding that this sentiment tends to be very strong. The subtopics for refusing vaccination were distrust in its safety, suspicion regarding its necessity, and fear of adverse effects or abnormal reactions.

The participants reported that people who strongly distrust the safety and efficacy of vaccination prefer to develop immunity naturally instead of obtaining immunity through vaccination. Pediatricians said that skepticism against vaccination is often rooted in distrust of the overall medical system, and people with such views often rely on information obtained from online communities and websites rather than by consulting doctors when making decisions.

Such individuals also deny the need for vaccination, and it can be even more difficult to convince them of the necessity of vaccinations that have limited effects or are accused of adverse effects. For instance, hesitancy about the influenza vaccination is common because of the inconvenience of receiving repeated administrations each year, its low credibility in terms of its effects, and the relatively low fear of the morbidity caused by influenza.

Parents whose child has experienced a reaction to a vaccina- 
tion sometimes refuse all recommended vaccinations, even if the symptoms were mild. Experiencing an abnormal reaction to vaccination in one child often leads to refusal of vaccination for the siblings as well. Parents of children with underlying diseases such as allergies or atopy, born as premature babies, with congenital diseases, suffering or recently recovered from a cold, or having recovered from Kawasaki disease are often concerned about the safety of vaccinations on a routine schedule. The experts agreed that parents can become extremely anxious and choose not to vaccinate their child when community health centers and medical institutions fail to provide consistent information on the safety of vaccination. This indicates the need to deliver accurate and consistent guidance to parents about when vaccinations can be carried out as scheduled and when they should be delayed.

\section{Personal circumstances that impede vaccination}

Representative examples of personal circumstances that impede vaccination were frequent overseas travel, double-income families, and low accessibility of medical institutions.

The community health center immunization administrators and pediatricians agreed that there have been insufficient efforts to encourage late vaccination if a scheduled vaccination is missed, leading to skipped vaccinations among those who frequently travel overseas. The multicultural family experts also confirmed that many children from multicultural families may miss vaccinations when visiting family members abroad.

Despite the improved accessibility provided by the expansion of the National Immunization Program, which enables free vaccinations at private institutions, double-income parents can have difficulty finding time to bring their children to an institution for vaccination.

It was found that low accessibility to public health centers or clinics in rural areas still serves as a roadblock to increased vaccination.

\section{Lack of information}

Multicultural family experts pointed to the language barrier and insufficient information as the biggest obstacles for such families. Immigrant women often go through pregnancy and birth without having enough time to adjust to Korean culture. They also tend to have limited social circles, which is another factor preventing them from accessing appropriate information. To make matters worse, text messages and other guidelines sent by the KCDC are only in Korean, meaning that such families miss essential advice, such as the importance of vaccination, the recommended immunization schedule, and free immunization clinics. It is vital to encourage these immigrants to visit the Multicultural Family Support Center or to contact the call center to obtain relevant information at an early stage of immigration and to make information available in both Korean and their mother tongue.

Meanwhile, community health center experts shared their difficulties in notifying patients of missed or upcoming scheduled vaccinations due to inaccurate contact information, arguing that a systemic update is necessary.

\section{Misclassification}

If a Korean citizen receives a vaccination abroad and does not submit proof of vaccination to a domestic community health center, the nation does not have an updated vaccination history of that person. This brings about challenges in confirming whether a person has actually been vaccinated, as well as difficulties in future management. Missing records were indicated as the major reason for missed vaccinations in certain regions where many of the residents have homes both in Korea and abroad or have recently returned to Korea.

In some cases, vaccinations performed by private institutions may not be reflected in the system. The pediatricians blamed the hard-to-navigate immunization history log system for such mistakes. To make matters worse, medical institutions not only are free from any legal duty to enter vaccination data, but also are not allowed to charge for the work of data entry, giving them excuses not to keep the data up to date.

\section{DISCUSSION}

The focus group interviews of 15 vaccination experts suggested 4 main obstacles to vaccination: (1) vaccine hesitancy, (2) personal circumstances that impede vaccination, (3) lack of information, and (4) misclassification. Among them, vaccine hesitancy was identified as the most significant factor that discourages vaccination, although there seemed to be a few unmet needs despite the accomplishments of the National Immunization Program. The interviews allowed real-life experiences and examples to be shared by experts who have been working towards improving the vaccination rate, and the discussions clearly produced meaningful directions regarding how to develop effective interventions to further enhance vaccination coverage. 
Previous domestic studies have sought to identify major barriers to vaccination in Korea. A study published in 2010 [8] surveyed 700 parents of children aged 2 to 5 who belonged to socially vulnerable groups and found that main reasons for non-vaccination were the child being sick during the vaccination period, the financial burden of vaccination, and unfamiliarity with the vaccination schedule. In another study, a phone survey was conducted of 1000 married women aged between 25 and 39 with children 12 years old and younger [9], who suggested that time spent on vaccination (31.7\%), high cost $(27.8 \%)$, and inconvenient community health center service hours (12.8\%) were their major complaints.

In contrast, in a 2012 study of 174 parents who skipped vaccinations for their children [10], the respondents stated that their main reasons were fear of possible side effects, suspicions regarding the necessity of vaccination, the child being sick during the vaccination period, the child having atopy, and preferring to acquire natural immunity, while only few replied with reasons of being unfamiliar with the vaccination schedule and being busy. In another study conducted in 2016 [11], 928 of 1254 newborns in 2012 who had missing vaccination records were found to have stayed abroad for an extended period of time. Other reasons included hesitancy about vaccination due to fear of possible side effects, suspicions regarding the necessity of vaccination, and personal or religious beliefs, followed by medical-related reasons such as reduced immunity, atopy, and underlying diseases that prevented vaccination. Only 2 people pointed to difficulties visiting medical institutions.

When comparing the conclusions of this study to previous studies, it seems that the major factors influencing vaccination have changed over time. Traditional barriers, including financial burdens and geographical accessibility, have been mostly replaced by new barriers, such as vaccine hesitancy and frequent overseas travel, as a result of the implementation of the National Immunization Program, the increased number of institutions providing free vaccination, and the notification service about upcoming vaccinations.

The younger generation, who has not experienced firsthand the risk of infectious diseases thanks to the triumph of successful vaccination programs that eliminated or reduced many epidemics, tend to fear such diseases less [12]. However, the same population is widely exposed to myths online regarding the risks and side effects of vaccines, leading them to become suspicious and distrustful toward immunization in general
$[13,14]$. In this context, more parents seem to refuse vaccination for their children due to fears of possible side effects, suspicions regarding the necessity and effectiveness of vaccination, distrust of vaccination, and a preference for natural immunity [12,15-22]. The World Health Organization (WHO) has recognized the gravity of this issue by defining such attitudes towards delaying or refusing vaccination due to issues of confidence, complacency, or convenience as "vaccine hesitancy" [23].

Missing vaccinations due to frequent overseas travel is one of the newest issues, reflecting an era in which going abroad is no longer a special occasion. The participants in our interviews suggested that notifications should be sent out to encourage those who missed a scheduled vaccination to get a shot nonetheless, and to promote the submission of certifications of vaccinations performed at overseas institutions to keep the system up-to-date. Some pointed out that institutionalizing the submission of a vaccination certification at the airport before and after travel would help manage vaccination in frequent travelers.

Meanwhile, the needs of children with underlying diseases, double-income parents, low accessibility to medical institutions in certain areas, and language and information barriers experienced by multicultural families have remained unmet, despite the continued efforts to enhance vaccination coverage rates.

An individual's attitudes and behaviors regarding vaccination are influenced by a combination of complex factors at multiple levels, including the cultural, social, and political context. Therefore, an integrated strategy including interactive communication through respected community organizations, legal groundwork, and structural reforms will be vital to address the unmet needs of vaccination [24-27], in addition to individual-level health communication [28].

This study also confirmed that various factors prevent individuals from receiving vaccinations, with each affecting a particular vulnerable group. Therefore, a one-size-fits-all solution would not be applicable to all cases. Rather, a tailored approach targeting each vulnerable group would be more effective for addressing the unmet needs and improving vaccination coverage rates. The WHO also recommends evidencebased interventions targeting certain vulnerable groups [29].

The study also reinforced the findings of previous studies that educated parents make up a surprisingly high percentage of the population with vaccine hesitancy [30]. They are known 
to request accurate information regarding side effects and efficacy directly from healthcare workers [31-33]. Thus, in order to improve the rate of vaccination coverage, healthcare workers should provide proper information based on facts and evidence concerning the belief that too many vaccinations could harm a child's immune system [34] and cause autism or autoimmune diseases [35-37], as well as whether vaccination during fever or atopy is safe. Healthcare providers are the point of contact for patients, and have the ability to bring about changes in their behavior. That is why efficient communication guidelines should be provided to healthcare workers [38] to promote efforts to build reliable relationships with patients and parents [12,39], and to deliver interventions via interactive communication $[27,40]$.

The limitations of this study include the possibility of reflecting only narrow points of view and the experiences of certain individuals. This issue is most prominent for the pediatricians, who accounted for only 2 participants. Both a private practitioner and a university hospital staff member were selected as participants to complement such limitations and to help the research team understand barriers in different practice environments. In addition, the private practitioner represented the voice of his colleagues as the chairman of the Korean Association of Pediatric Practitioners, and the university hospital pediatrician also represented the opinions of the Korea Pediatric Society.

Despite such limitations, the focus group interviews provided an in-depth understanding of the attitudes, perceptions, and beliefs of parents who do not vaccinate their children through a qualitative approach. Fundamental roadblocks to vaccination were identified through the vivid experiences shared by the participants, who were experts working at vaccination sites. Hopefully, the results of this study can be used to establish a more tailored intervention strategy that can further increase the rate of vaccination coverage in Korea.

\section{ACKNOWLEDGEMENTS}

This research was supported by a grant from the Korean Centers for Disease Control and Prevention in 2016 (2016-E33004-00).

\section{CONFLICT OF INTEREST}

The authors have no conflicts of interest associated with the material presented in this paper.

\section{ORCID}

Bomi Park https://orcid.org/0000-0001-5834-9975

Eun Jeong Choi https://orcid.org/0000-0002-7698-3424

Bohyun Park https://orcid.org/0000-0002-8538-9662

Hyejin Han http://orcid.org/0000-0002-1669-3177

Su Jin Cho https://orcid.org/0000-0002-3851-9073

Hee Jung Choi https://orcid.org/0000-0002-1468-4074

Seonhwa Lee https://orcid.org/0000-0002-9134-6319

Hyesook Park http://orcid.org/0000-0002-9359-6522

\section{REFERENCES}

1. Campos-Outcalt D. Immunization update: what's changed, what's on the way. J Fam Pract 2015;64(3):177-180.

2. Khabbaz RF, Moseley RR, Steiner RJ, Levitt AM, Bell BP. Challenges of infectious diseases in the USA. Lancet 2014;384(9937): 53-63.

3. Korea Centers for Disease Control and Prevention. National childhood vaccination coverage among children aged 3 years in Korea 2017; 2016 [cited 2017 Jul 27]. Available from: http:// www.cdc.go.kr/CDC/info/CdcKrinfo0726.jsp?menulds = HOME001-MNU1132-MNU2430-MNU2689\&fid $=9254 \& q_{-}$ type $=\& q \_$value $=\&$ cid $=75612 \&$ pageNum $=$ (Korean $)$.

4. Smith M. Vaccine safety: medical contraindications, myths, and risk communication. Pediatr Rev 2015;36(6):227-238.

5. Krueger RA, Casey MA. Focus groups: a practical guide for applied research. 3rd ed. Thousand Oaks: Sage Publications; 2000, p. 3-27.

6. Tong A, Sainsbury P, Craig J. Consolidated criteria for reporting qualitative research (COREQ): a 32-item checklist for interviews and focus groups. Int J Qual Health Care 2007;19(6): 349-357.

7. Braun V, Clarke V. Using thematic analysis in psychology. Qual Res Psychol 2006;3(2):77-101.

8. Park HS. Vaccination coverage and barriers in hard to reach children. Cheongju: Korea Centers for Disease Control and Prevention; 2010, p. 10 (Korean).

9. Lee SK. Evaluation of national burden project for essential national vaccination cost. Cheongju: Korea Centers for Disease Control and Prevention; 2010, p. 143 (Korean).

10. Yoon SJ. Strategic proposal for the improvement of immunization by the immunization program evaluation. Seoul: Ministry of Health and Welfare; 2012, p. 87-88 (Korean)

11. Lee SK. Investigation and management of children with no 
vaccinations recorded on the national immunization registry information system. Cheongju: Korea Centers for Disease Control and Prevention; 2016, p. 32-33 (Korean).

12. Edwards KM, Hackell JM; Committee on Infectious Diseases, the Committee on Practice and Ambulatory Medicine. Countering vaccine hesitancy. Pediatrics 2016;138(3):e20162146.

13. Choi I, Chung M, Choy S, Kim S. Information sources and knowledge on infant vaccination according to online communities. J Prev Med Public Health 2007;40(4):291-296 (Korean).

14. Rosselli R, Martini M, Bragazzi NL. The old and the new: vaccine hesitancy in the era of the Web 2.0. Challenges and opportunities. J Prev Med Hyg 2016;57(1):E47-E50.

15. Hough-Telford C, Kimberlin DW, Aban I, Hitchcock WP, Almquist J, Kratz R, et al. Vaccine delays, refusals, and patient dismissals: a survey of pediatricians. Pediatrics 2016;138(3): e20162127.

16. Dubé E, Gagnon D, Ouakki M, Bettinger JA, Guay M, Halperin S, et al. Understanding vaccine hesitancy in Canada: results of a consultation study by the Canadian Immunization Research Network. PLoS One 2016;11(6):e0156118.

17. de St Maurice A, Edwards KM. Vaccine hesitancy in children-a call for action. Children (Basel) 2016;3(2):7.

18. Rhim JW, Kim CH, Lee WB, Kang JH. A survey of parental knowledge of vaccination. Korean J Pediatr 2006;49(3):251257 (Korean).

19. Larson HJ, Jarrett C, Eckersberger E, Smith DM, Paterson P. Understanding vaccine hesitancy around vaccines and vaccination from a global perspective: a systematic review of published literature, 2007-2012. Vaccine 2014;32(19):2150-2159.

20. McCauley MM, Kennedy A, Basket M, Sheedy K. Exploring the choice to refuse or delay vaccines: a national survey of parents of 6- through 23-month-olds. Acad Pediatr 2012;12(5): 375-383.

21. Gust DA, Darling N, Kennedy A, Schwartz B. Parents with doubts about vaccines: which vaccines and reasons why. Pediatrics 2008;122(4):718-725.

22. Sandhofer MJ, Robak O, Frank H, Kulnig J. Vaccine hesitancy in Austria: a cross-sectional survey. Wien Klin Wochenschr 2017; 129(1-2):59-64.

23. World Health Organization. Report of the SAGE working group on vaccine hesitancy; 2014 [cited 2018 Jun 12]. Available from: http://www.who.int/immunization/sage/meetings/2014/october/1_Report_WORKING_GROUP_vaccine_ hesitancy_final.pdf.
24. Yoo BK. How to improve influenza vaccination rates in the U.S. J Prev Med Public Health 2011;44(4):141-148.

25. Dubé E, Gagnon D, MacDonald NE; SAGE Working Group on Vaccine Hesitancy. Strategies intended to address vaccine hesitancy: review of published reviews. Vaccine 2015;33(34): 4191-4203.

26. Thomson A, Watson M. Vaccine hesitancy: a vade mecum v1.0. Vaccine 2016;34(17):1989-1992.

27. MacDonald NE; SAGE Working Group on Vaccine Hesitancy. Vaccine hesitancy: definition, scope and determinants. Vaccine 2015;33(34):4161-4164.

28. Health Communication Capacity Collaborative. The P process: five steps to strategic communication; 2013 [cited 2018 Jun 18]. Available from: http://www.healthcommcapacity.org/ wp-content/uploads/2014/04/P-Process-Brochure.pdf.

29. World Health Organization Regional Office for Europe. Guide to tailoring immunization programmes; 2013 [cited $2018 \mathrm{Apr}$ 8]. Available from: http://www.euro.who.int/en/health-topics/communicable-diseases/poliomyelitis/publications/2013/ guide-to-tailoring-immunization-programmes.

30. Gullion JS, Henry L, Gullion G. Deciding to opt out of childhood vaccination mandates. Public Health Nurs 2008;25(5): 401-408.

31. Smith PJ, Kennedy AM, Wooten K, Gust DA, Pickering LK. Association between health care providers' influence on parents who have concerns about vaccine safety and vaccination coverage. Pediatrics 2006;118(5):e1287-e1292.

32. Smailbegovic MS, Laing GJ, Bedford H. Why do parents decide against immunization? The effect of health beliefs and health professionals. Child Care Health Dev 2003;29(4):303-311.

33. Kennedy A, Basket M, Sheedy K. Vaccine attitudes, concerns, and information sources reported by parents of young children: results from the 2009 HealthStyles survey. Pediatrics 2011;127 Suppl 1:S92-S99.

34. Gellin BG, Maibach EW, Marcuse EK. Do parents understand immunizations? A national telephone survey. Pediatrics 2000; 106(5):1097-1102.

35. Zimmerman RK, Wolfe RM, Fox DE, Fox JR, Nowalk MP, Troy JA, et al. Vaccine criticism on the world wide web. J Med Internet Res 2005;7(2):e17.

36. Ventola CL. Immunization in the United States: recommendations, barriers, and measures to improve compliance. Part 1: childhood vaccinations. P T 2016;41(7):426-436.

37. Kimmel SR, Burns IT, Wolfe RM, Zimmerman RK. Addressing immunization barriers, benefits, and risks. J Fam Pract 2007; 
56(2 Suppl Vaccines):S61-S69.

38. Goldstein S, MacDonald NE, Guirguis S; SAGE Working Group on Vaccine Hesitancy. Health communication and vaccine hesitancy. Vaccine 2015;33(34):4212-4214.

39. Kempe A, Daley MF, McCauley MM, Crane LA, Suh CA, Kennedy $\mathrm{AM}$, et al. Prevalence of parental concerns about childhood vaccines: the experience of primary care physicians. Am J Prev Med 2011;40(5):548-555.

40. Opel DJ, Heritage J, Taylor JA, Mangione-Smith R, Salas HS, Devere $V$, et al. The architecture of provider-parent vaccine discussions at health supervision visits. Pediatrics 2013;132(6): 1037-1046. 